\title{
Combination of Statistical Techniques for Submerged Fermentation for Extracellular Polysaccharide and Biomass of Ganoderma tsugae
}

\author{
${ }^{1}$ Nukrob Narkprasom, ${ }^{2}$ Jia-Hsin Guo, ${ }^{2,3}$ Tzou-Chi Huang, ${ }^{2}$ Yuan-Kuang Guu \\ ${ }^{1}$ Faculty of Engineering and Agro-Industry, Maejo University, Chiang Mai, Thailand \\ ${ }^{2}$ Department of Food Science, National Pingtung University of Science and Technology, Pingtung, Taiwan \\ ${ }^{3}$ Department of Biological Science and Technology, National Pingtung University of Science and Technology, Taiwan
}

Received 2014-06-27; Revised 2014-06-30; Accepted 2014-07-04

\begin{abstract}
Biomass and extracellular polysaccharide of Ganoderma tsugae have various biological activity including anti-inflamatory activity, antioxidant activity and antitumor activity. However, the growth rate of G. tsugae in nature is very slow. Therefore, many studies have attempted to develop mass culture systems for $G$. tsugae using laboratory techniques. Many parameters of submerged fermentation for G. tsugae were studies to determine the optimization of process by combination of statistical techniques. Ten parameters from preliminary results and literature reviews (maltose, skim milk, $\mathrm{KH}_{2} \mathrm{PO}_{4}+\mathrm{K}_{2} \mathrm{HPO}_{4}, \mathrm{MgSO}_{4}-7 \mathrm{H}_{2} \mathrm{O}, \mathrm{CaCO}_{3}$, vitamin $\mathrm{B}_{5}+\mathrm{B}_{6}$, olive oil, ethanol, $\mathrm{pH}$ and shaking speed) were screened by Packett Berman design. The significant parameters were determined the optimal ranges by path of steepest ascent method. The optimal condition of process was performed by response surface method. Maltose, skim milk and $\mathrm{pH}$ are significant parameters for G. tsugae cultivation. The conditions of $31.031 \mathrm{~g} \mathrm{~L}^{-1}$ maltose, $14.055 \mathrm{~g} \mathrm{~L}^{-1}$ skim milk and an initial $\mathrm{pH}$ of 7.12 resulted in the maximum extracellular polysaccharide content of $415 \mathrm{mg} \mathrm{L}^{-1}$ and the same fermentation broth at an initial $\mathrm{pH}$ of 6.46 exhibited the most biomass at $15.776 \mathrm{~g} \mathrm{~L}^{-1}$. Finally, the optimal condition was compared with un-optimal condition which result indicates that the combination of statistical techniques enhance the productions of biomass and extracellular polysaccharide $(13 \mathrm{X}$ and $1.5 \mathrm{X}$ of the control, respectively). Therefore, these strategies are useful for improvement of submerged fermentation of G. tsugae which it can apply in pharmaceutical industry.
\end{abstract}

Keywords: Ganoderma Tsugae, Plackett Burman Design, Steepest Ascent Method, Response Surface Method

\section{INTRODUCTION}

Song San Ling Chih or Ganoderma tsugae has been as a traditional medicine which it is used to promote of health and longevity in Asian countries (Lin et al., 2013). The polysaccharides produced by $G$. tsugae have been studied and used for pharmaceutical purposes as treatment for various diseases (Hsu et al., 2009) and have been applied to add in the food and medicinal industries (Rusell and Paterson, 2006). The cultivation of $G$. tsugae for fruiting body takes a long period and high risk of contamination from nature. Therefore, technique of submerged fermentation was interested from bio- pharmaceutical industry, because it has short time cultivation, easy to control condition for contaminated protection and obtain best product in quality and quantity (Narkprasom et al., 2012). The production yield of $G$. tsugae cultured using submerged fermentation is affected by many parameters, such as agitation, aeration, temperature, $\mathrm{pH}$, dissolved oxygen, nutrient composition and fermentation time (Chang et al., 2006; Hsieh et al., 2006; Yang et al., 2004; Lee et al., 2003) and these parameters are critical for the production of $G$. tsugae. The optimization method for many parameters in fermentation process of $G$. tsugae has attracted significant interest from pharmaceutical industry. The Corresponding Author: Nukrob Narkprasom, Faculty of Engineering and Agro-Industry, Maejo University, Chiang Mai, Thailand 
combination of statistical techniques including screening by Plackett Burman Design (PBD), determining optimal variable ranges by steepest ascent method and performing optimal searching by Response Surface Method (RSM) have been applied to optimize biochemical and physical processes in many studies (Omar et al., 2004; Xu et al., 2008; Cansee et al., 2008; Xiao et al., 2010; Zhang et al., 2010) because of reasonable study design and excellent outcomes. Therefore, the aims of this report were to determine the optimal condition of submerged fermentation for Extracellular Polysaccharide (EPS) and mass cultivation of Ganoderma tsugae by combination of statistical techniques.

\section{MATERIALS AND METHODS}

\subsection{Inoculums Preparation and Submerged Culture}

G. tsugue BCRC 36203 in stock was culture with potato dextrose with agar in a Petri dish at $28^{\circ} \mathrm{C}$ for 7 days. After that, the mycelium was transfer to Erlenmeyer flask with $200 \mathrm{~mL}$ of potato dextrose broth at $30^{\circ} \mathrm{C}$ for 7 days. The mycelia pellet was crushed with sterilized bender and then transferred to various flasks with different experimental conditions (10 mL per flask) at $30^{\circ} \mathrm{C}$ for 5 days. The cultured products were separated between mycelia pellets and supernatant by centrifugation at $15,000 \times \mathrm{g}$ for $20 \mathrm{~min}$. The supernatant and precipitate were used to determine the EPS and dry cell weight of biomass, respectively. The precipitate was dried by freeze dry and EPS was determined by phenol-sulfuric acid method with a spectrophotometer reading at $490 \mathrm{~nm}$.

\subsection{Statistical Experimental Design for Optimization of Submerged Fermentation}

Statistical experimental design procedure used here to optimize medicinal fungus production can be subdivided into four steps: (i) Identification of the most important media components (screening), (ii) identification of the optimal variable ranges (narrowing), (iii) identification of the optimum conditions (optimum search) and (iv) experimental verification of the identified optimum (verification).

\subsection{Screening for Important Parameters}

PBD is generally used to identify the most important media components. A two-level fractional factorial design for studying $n-1$ variables in $n$ runs is an effective method to rapidly identify the most significant parameters. One-variable-at-a-time experiments identified many principal parameters affecting the EPS production of $G$. tsugae: Maltose, skim milk, $\mathrm{KH}_{2} \mathrm{PO}_{4}$, $\mathrm{K}_{2} \mathrm{HPO}_{4}, \mathrm{MgSO}_{4} \cdot 7 \mathrm{H}_{2} \mathrm{O}, \mathrm{CaCO}_{3}$, vitamin $\mathrm{B}_{5}+\mathrm{B}_{6}$, olive oil, ethanol, initial $\mathrm{pH}$ and shaking speed. The combined effects of these variables were evaluated using a PBD with a firstorder polynomial equation. Each independent variable was tested at low $(-1)$ and high $(+1)$ levels. Different combinations of variables were tested in 12 experimental runs. The fitted first-order model is Equation 1:

$$
Y=\beta_{0}+\sum \beta_{i} x_{i}
$$

where, $Y$ is the predicted response, $\beta_{0}$ and $\beta_{i}$ are constant coefficients and $x_{i}$ represents the coded independent variables. Each experiment was carried out in triplicate and the average value was taken as the response. Variables with confidence levels above $95 \%$ were considered to have significant effects on the EPS production and therefore were used for further optimization.

\subsection{Narrowing Optimal Variable Ranges}

Method of steepest ascent is often used to identify the optimal variable range. To approach the maximum response region of a variable, the key variables screened by the PBD were further optimized via a path of steepest ascent. This procedure allows for sequential movement towards the maximum response. The path of steepest ascent was initiated from the mid-point values of each major factor identified by the PBD.

\subsection{Optimum Search}

Because the location of the optimum within the experimental range is unknown prior to RSM, a rotational design can be employed that allows for estimation with equal precision in all directions. Based on the approximate central point of a RSM, the optimum region was obtained through a path of steepest ascent. RSM was employed here to screen for the optimum levels of the three most significant factors identified by the PBD where it was assumed that the estimated response surface $\mathrm{Y}$ could be described with the aid of a second-order polynomial Equation 2:

$$
Y=\beta_{0}+\sum \beta_{i} x_{i}+\sum \beta_{i j} x_{i} x_{j}+\sum \beta_{i i} x_{i}^{2}
$$

To allow for an unconfounded estimation of the regression coefficients $\beta$, each parameter must be examined on at least three levels. To determine the regression coefficients of the second-order polynomial 
using the fewest possible experiments, different experimental designs were proposed that differed in the number of minimum necessary experiments and in the range of application.

\subsection{Verification of Model}

High production of $G$. tsugae calculated from the quadratic equations of the RSM must be demonstrated experimentally to verify the optimal condition to confirm the results and also compare the yields of the optimized and unoptimized conditions.

\subsection{Statistical Analysis and Software}

In combinatorial experimental designs, the all regression analysis of the experimental data were calculated using Microsoft Excel 2007. Sigma Plot 10 was used to create the $3 \mathrm{D}$ graphs to present the results of RSM experiment.

\section{RESULTS}

Base on preliminary results, carbon source as maltose, nitrogen source as skim milk and vitamin $\mathrm{B}_{5}+\mathrm{B}_{6}$ were nutrients used during fermentation screening by PBD, whereas the other nutrients and fermenting conditions were set base on literature reviews.

\subsection{Fermentation Condition Screening}

Twelve runs by PBD were carried out to determine the effects of these ten variables on EPS production. As shown in Table 1, high EPS yields ranging from 93.045$167.009 \mathrm{~m} \mathrm{~g} \mathrm{~L}^{-1}$ were obtained. A first-order model was generated as follows Equation 3:

$$
\begin{aligned}
& Y_{E P S}=127 .+14.825 x_{1}+10.560 x_{2}+5.419 x_{3}- \\
& 3.140 x_{4}+4.689 x_{5}+2.293 x_{6}-7.464 x_{7}-2.994 x_{8}+ \\
& 10.356 x_{9}+3.286 x_{10}
\end{aligned}
$$

The fitness of model was evaluated from the coefficient of determination $R^{2}$. The $R^{2}$ value from Eq. 3 shows that $98.04 \%$ of the total variance of the system could be explained by the model (Table 2).

\subsection{Determination of Optimal Ranges}

As shown in Table 2, maltose, skim milk and $\mathrm{pH}$ were found to correlate positively with EPS production. The path of steepest ascent was determined, starting from the midpoint established from PBD, by increasing $\mathrm{pH}$ and the concentrations of maltose and skim milk. The results of this experiment are shown in Table 3. The maximum EPS yield of $338.249 \mathrm{mg} \mathrm{L}^{-1}$ with a biomass of $9.430 \mathrm{~g} \mathrm{~L}^{-1}$ was obtained under the following conditions: 30 $\mathrm{g} \mathrm{L}^{-1}$ of maltose, $11 \mathrm{~g} \mathrm{~L}^{-1}$ skim milk and $\mathrm{pH}$ 6.70. These experimental results were used to determine the optimal variable ranges, which were then used to design a search for optimum by response surface method.

\subsection{Optimization Searching}

Central composite design (CCD) by RSM is a very useful tool to determine the optimal level of medium constituents and their interactions. The results of CCD experiments with different combinations of maltose $\left(\mathrm{x}_{1}\right)$, skim milk $\left(\mathrm{x}_{2}\right)$ and initial $\mathrm{pH}\left(\mathrm{x}_{3}\right)$ are presented along with the mean predicted and experimental values in Table 4.

\subsection{Optimization of EPS Production of G. Tsugae}

Changing fermentation conditions led to considerable variation in the yield of EPS. Using the multiple regression analysis method, the predicted response for the EPS can be described by Equation 4:

$$
\begin{aligned}
& Y_{E P S}=374.199+28.950 x_{1}+21.644 x_{2}+43.411 x_{3}- \\
& 22.763 x_{1} x_{2}+2.476 x_{1} x_{3}+19.652 x_{2} x_{3}-21.422 x_{1}^{2}- \\
& 20.307 x_{1}^{2}-25.729 x_{3}^{2}
\end{aligned}
$$

where, $Y_{E P S}$ is the EPS yield and $\mathrm{x}_{1}, \mathrm{x}_{2}$ and $\mathrm{x}_{3}$ are the coded factors of maltose, skim milk and initial $\mathrm{pH}$, respectively. The quadratic regression model for EPS was demonstrated to be highly significant (F-test < 0.0001 ). The adjusted $\mathrm{R}^{2}$ value suggested that the total variation of $96 \%$ for the yield of EPS was attributed to the independent variables and only about $4 \%$ of the total variation could not be explained by the model.

$\mathrm{R}^{2}$ value closer to 1 indicate a better correlation between the experimental and predicted values. The $\mathrm{R}^{2}$ value of 0.9917 indicated good agreement between the experimental and predicted EPS values. To better understand the effects of EPS of G. tsugae, the model was calculated using RSM.

The 3D response surface plots were presented in Fig. 1 to visualise interactions between the variables and rapidly estimate the optimal value of each variable for EPS production. Fig. 1 shows the combined effects of two variables, while the remaining variables were maintained at constant levels. By solving Eq. 4, the model predicted a maximum EPS yield of $415.178 \mathrm{mg}$ $\mathrm{L}^{-1}$ when the coded levels of the three most significant variables were $\mathrm{x}_{1}=0.2064, \mathrm{x}_{2}=1.0185$ and $\mathrm{x}_{3}=1.243$, representing maltose, skim milk and initial $\mathrm{pH}$ values of $31.0319 \mathrm{~g} \mathrm{~L}^{-1}, 14.0555 \mathrm{~g} \mathrm{~L}^{-1}$ and 7.12 . 
Central Composite Design (CCD) by RSM is a very useful tool to determine the optimal level of medium constituents and their interactions. The results of CCD experiments with different combinations of maltose $\left(\mathrm{x}_{1}\right)$, skim milk $\left(\mathrm{x}_{2}\right)$ and initial $\mathrm{pH}\left(\mathrm{x}_{3}\right)$ are presented along with the mean predicted and experimental values in Table 4.

\subsection{Optimization of biomass production of $G$. Tsugae}

By applying multiple regression analysis on the experimental data reported in Table 4, the secondorder polynomial equation for mycelium biomass was written as follows:

$$
\begin{aligned}
& Y_{\text {Biomass }}=13.506+0.697 x_{1}+2.971 x_{2}-1.253 x_{3}- \\
& 0.832 x_{1} x_{2}+0.110 x_{1} x_{3}+0.723 x_{2} x_{3}-1.812 x_{1}^{2}-0.994 x_{2}^{2} \\
& -0.931 x_{3}^{2}
\end{aligned}
$$

where, $Y_{\text {Biomass }}$ is the predicted biomass yield of $G$. tsugae in submerged fermentation and $\mathrm{x}_{1}, \mathrm{x}_{2}$ and $\mathrm{x}_{3}$ are the coded factors of maltose, skim milk and initial $\mathrm{pH}$, respectively. The results of the regression analysis for biomass production are shown in Table 4. The adjusted $\mathrm{R}^{2}$ of the second-order polynomial Equation 5 was
0.9470. The high values of multiple $\mathrm{R}^{2}(0.9859)$ and determinant coefficient $\mathrm{R}^{2}(0.9721)$ show that the values predicted by model are close to the experimental data. To study effects of variables on biomass of $G$. tsugae, the predicted model was further assessed using CCD response surface analysis. The different input levels of maltose, skim milk and $\mathrm{pH}$ on the subsequent biomass production of G. tsugae were shown on Fig. 2. All 3D graphs indicate a quadratic function rather than a linear function. Solving for the variables of Eq. 5, the optimal values of test variables in actual units were $29.189 \mathrm{~g} \mathrm{~L}^{-1}$ maltose, $15.603 \mathrm{~g} \mathrm{~L}^{-1}$ skim milk and an initial $\mathrm{pH}$ of 6.46. This condition was associated with the maximum predicted amount of mycelium biomass from G. tsugae in submerged fermentation, $15.776 \mathrm{~g} \mathrm{~L}^{-1}$.

\subsection{Verification of Model}

The model was confirmed by, comparing optimal and non-optimal conditions. Table 5 shows that the EPS and biomass production were found to be very close to the predicted values, supporting the accuracy of the model. Moreover, the optimal experimental conditions enhanced the biomass and EPS production of G. tsugae 13-fold and 1.5-fold, respectively, when compared with a non-optimized condition.

Table 1. Plackett Burman design for screening of significant factors affecting EPS of G. tsugae

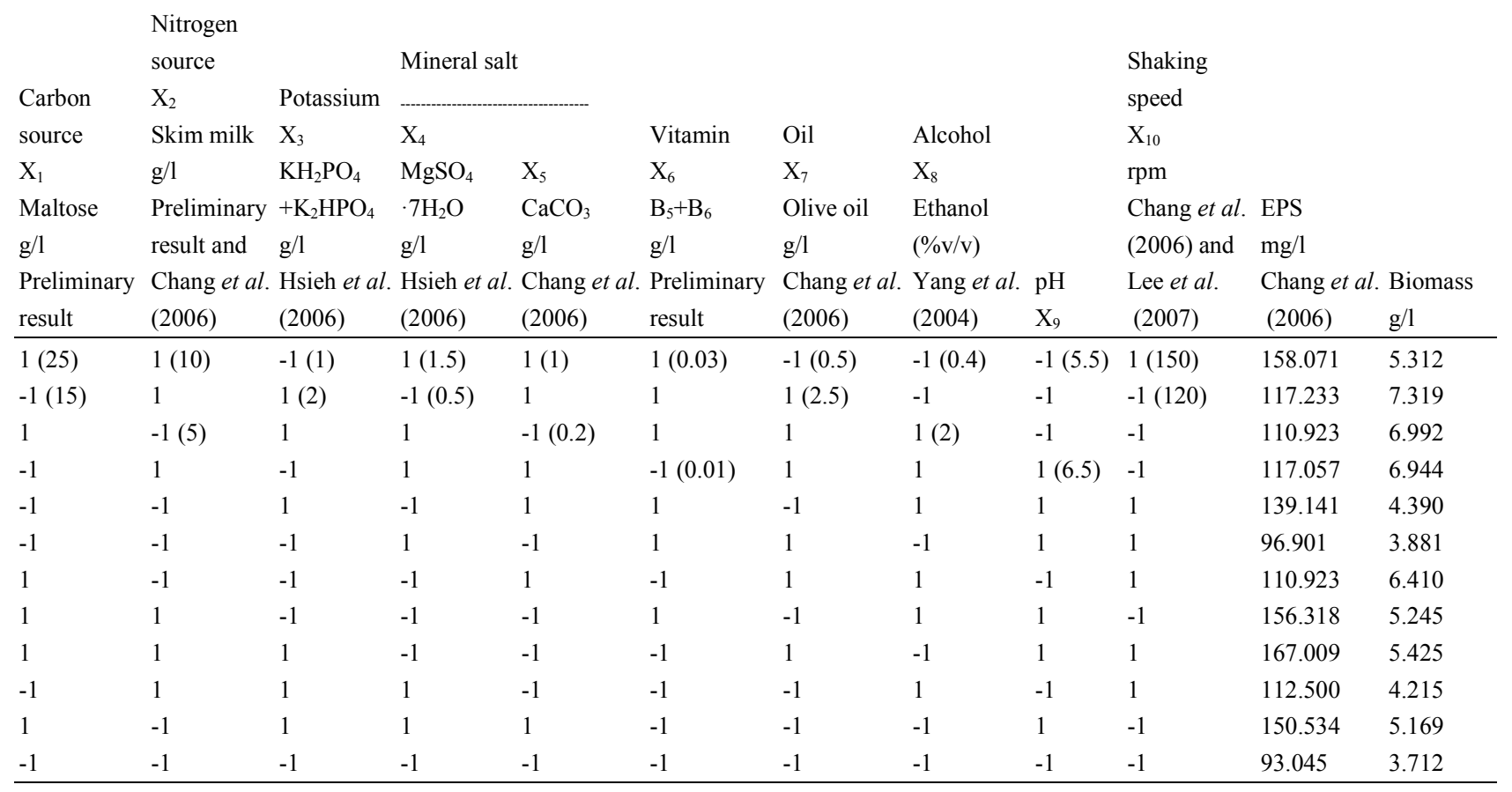


Nukrob Narkprasom et al. / American Journal of Biostatistics 3 (2): 38-46, 2013

Table 2. Plackett Burman design for screening variables of EPS from G. tsugae

\begin{tabular}{lccccc}
\hline Variables & Low level (-1) & High level $(+1)$ & Coefficients & P-value & Confidence level \\
\hline $\mathrm{X}_{1}$ & 15.00 & 25.00 & 14.825 & 4.356 & $85.635^{*}$ \\
$\mathrm{X}_{2}$ & 5.00 & 10.00 & 10.560 & 3.103 & $80.153^{*}$ \\
$\mathrm{X}_{3}$ & 1.00 & 2.00 & 5.419 & 1.592 & 64.300 \\
$\mathrm{X}_{4}$ & 0.50 & 1.50 & -3.140 & -0.923 & 47.444 \\
$\mathrm{X}_{5}$ & 0.20 & 1.00 & 4.689 & 1.378 & 60.029 \\
$\mathrm{X}_{6}$ & 0.01 & 0.03 & 2.293 & 0.674 & 37.748 \\
$\mathrm{X}_{7}$ & 0.50 & 2.50 & -7.464 & -2.193 & 72.765 \\
$\mathrm{X}_{8}$ & 1.40 & 2.00 & -2.994 & -0.880 & 45.936 \\
$\mathrm{X}_{9}$ & 5.50 & 6.50 & 10.356 & 3.043 & $79.787 *$ \\
$\mathrm{X}_{10}$ & 120.00 & 150.00 & 3.286 & 0.966 & 48.888 \\
\hline
\end{tabular}

Multiple R $=0.9902, \mathrm{R} 2=0.9804$, Adjusted $\mathrm{R}=0.7848$, Standard Error $=3.403$

Table 3. Experimental design and results along the steepest ascent for EPS production of G. tsugae

\begin{tabular}{lccccc}
\hline Step & Maltose $(\mathrm{g} / \mathrm{l}), \mathrm{x}_{1}$ & Skim milk $(\mathrm{g} / \mathrm{l}), \mathrm{x}_{2}$ & $\mathrm{pH}, \mathrm{x}_{9}$ & $\mathrm{EPS}(\mathrm{mg} / \mathrm{l})$ & Biomass $(\mathrm{g} / \mathrm{l})$ \\
\hline 1 & 20 & 7.500 & 6.00 & 238.169 & 3.099 \\
2 & 25 & 9.281 & 6.35 & 245.921 & 4.495 \\
3 & 11.062 & 6.70 & 338.249 & 9.430 \\
4 & 12.842 & 7.05 & 284.266 & 5.124 \\
5 & 35 & 14.623 & 7.40 & 254.135 & 2.369 \\
\hline
\end{tabular}

Table 4. Experimental design and results of the central composite design for optimization of the EPS production and biomass

\begin{tabular}{|c|c|c|c|c|c|c|c|}
\hline \multirow[b]{2}{*}{ Run } & \multirow{2}{*}{$\begin{array}{l}\text { Maltose }(\mathrm{g} / \mathrm{l}) \\
\mathrm{X}_{1}\end{array}$} & \multirow{2}{*}{$\begin{array}{l}\text { Skim milk }(\mathrm{g} / \mathrm{l}) \\
\mathrm{X}_{2}\end{array}$} & \multirow{2}{*}{$\begin{array}{l}\mathrm{pH} \\
\mathrm{X}_{3} \\
\end{array}$} & \multicolumn{2}{|l|}{ EPS (mg/l) } & \multicolumn{2}{|c|}{ Biomass (g/l) } \\
\hline & & & & Measured & Predicted & Measured & Predicted \\
\hline 1 & $-1(25)$ & $-1(8)$ & $-1(6)$ & 211.879 & 212.100 & 7.413 & 7.339 \\
\hline 2 & $1(35)$ & -1 & -1 & 315.464 & 310.575 & 9.660 & 10.175 \\
\hline 3 & -1 & $1(14)$ & -1 & 275.327 & 261.611 & 12.867 & 13.496 \\
\hline 4 & 1 & 1 & -1 & 270.945 & 269.033 & 12.140 & 13.006 \\
\hline 5 & -1 & -1 & $1(7)$ & 261.655 & 254.666 & 3.707 & 3.201 \\
\hline 6 & 1 & -1 & 1 & 358.230 & 363.044 & 6.747 & 6.478 \\
\hline 7 & -1 & 1 & 1 & 386.799 & 382.786 & 12.407 & 12.252 \\
\hline 8 & 1 & 1 & 1 & 409.233 & 400.111 & 11.767 & 12.202 \\
\hline 9 & $-1.682(21.6)$ & $0(11)$ & $0(6.5)$ & 254.645 & 264.919 & 6.973 & 7.210 \\
\hline 10 & $1.682(38.4)$ & 0 & 0 & 359.982 & 362.296 & 10.300 & 9.553 \\
\hline 11 & $0(30)$ & $-1.682(6.8)$ & 0 & 280.585 & 280.361 & 5.327 & 5.699 \\
\hline 12 & 0 & $1.682(15.2)$ & 0 & 340.352 & 353.164 & 16.573 & 15.691 \\
\hline 13 & 0 & 0 & $-1.682(5.66)$ & 220.642 & 228.418 & 13.927 & 12.949 \\
\hline 14 & 0 & 0 & $1.682(7.34)$ & 369.622 & 374.434 & 8.327 & 8.794 \\
\hline 15 & 0 & 0 & 0 & 372.426 & 374.199 & 13.533 & 13.506 \\
\hline 16 & 0 & 0 & 0 & 370.148 & 374.199 & 13.847 & 13.506 \\
\hline 17 & 0 & 0 & 0 & 387.149 & 374.199 & 14.253 & 13.506 \\
\hline 18 & 0 & 0 & 0 & 360.333 & 374.199 & 12.760 & 13.506 \\
\hline 19 & 0 & 0 & 0 & 378.911 & 374.199 & 12.853 & 13.506 \\
\hline 20 & 0 & 0 & 0 & 378.386 & 374.199 & 13.700 & 13.506 \\
\hline
\end{tabular}


Nukrob Narkprasom et al. / American Journal of Biostatistics 3 (2): 38-46, 2013

Table 5. Comparison between G. tsugae production in non-optimized and optimise conditions

\begin{tabular}{llll}
\hline Non-optimized conditions from the initial basal medium $^{\text {a }}$ & EPS (mg/l) & $274.904 \pm 67.452$ & \\
\hline & Biomass (g/l) & $1.183 \pm 0.276$ & \\
Optimal condition $^{\mathrm{b}}$ & EPS (mg/l) & Measured & $416.244 \pm 14.801$ \\
& & Predicted & 415.178 \\
& Biomass (g/l) & Measured & $15.701 \pm 0.323$ \\
& & Predicted & 15.534 \\
\hline
\end{tabular}

${ }^{\mathrm{a}}$ Glucose $20 \mathrm{~g} \mathrm{~L}^{-1}$, Peptone $7.5 \mathrm{~g} \mathrm{~L}^{-1}$, KH2PO4 and K2HPO4 $1.5 \mathrm{~g} \mathrm{~L}^{-1}, \mathrm{MgSO} 4 \cdot 7 \mathrm{H} 2 \mathrm{O} 1 \mathrm{~g} \mathrm{~L}^{-1}$ and $150 \mathrm{rpm}$

${ }^{\mathrm{b}}$ Maltose $30 \mathrm{~g} \mathrm{~L}^{-1}$, Skim milk14 $\mathrm{g} \mathrm{L}^{-1}$, KH2PO4 and K2HPO41.5 $\mathrm{g} \mathrm{L}^{-1}$, MgSO4•7H2O $1 \mathrm{~g} \mathrm{~L}^{-1}, \mathrm{CaCO}_{0.6} \mathrm{~g} \mathrm{~L}^{-1}$, Vitamins $\mathrm{B} 5$ and $\mathrm{B} 60.02 \mathrm{~g} \mathrm{~L}^{-1}$, Olive oil $1.5 \mathrm{~g} \mathrm{~L}^{-1}$, Ethanol $1.2 \mathrm{~g} \mathrm{~L}^{-1}, \mathrm{pH} 7$ and $135 \mathrm{rpm}$

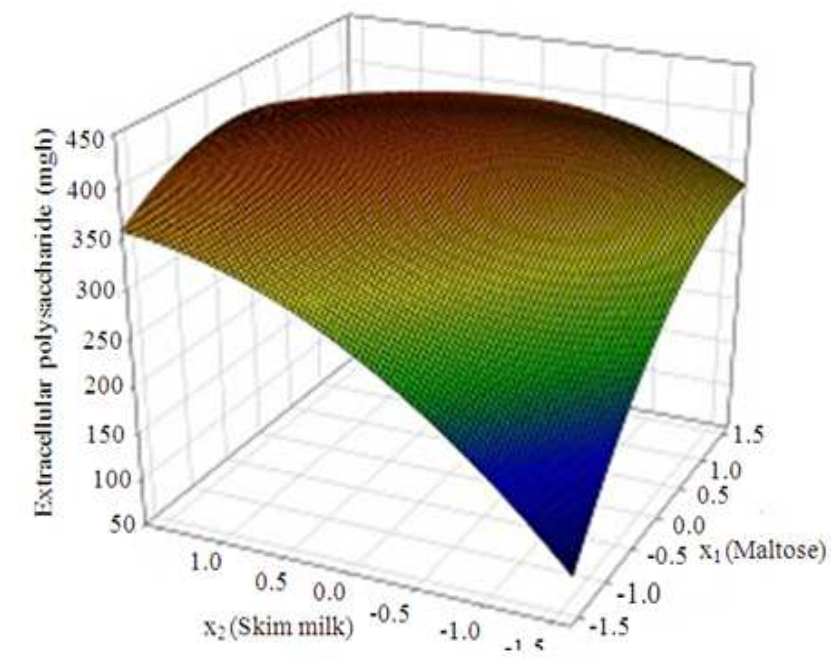

(a)

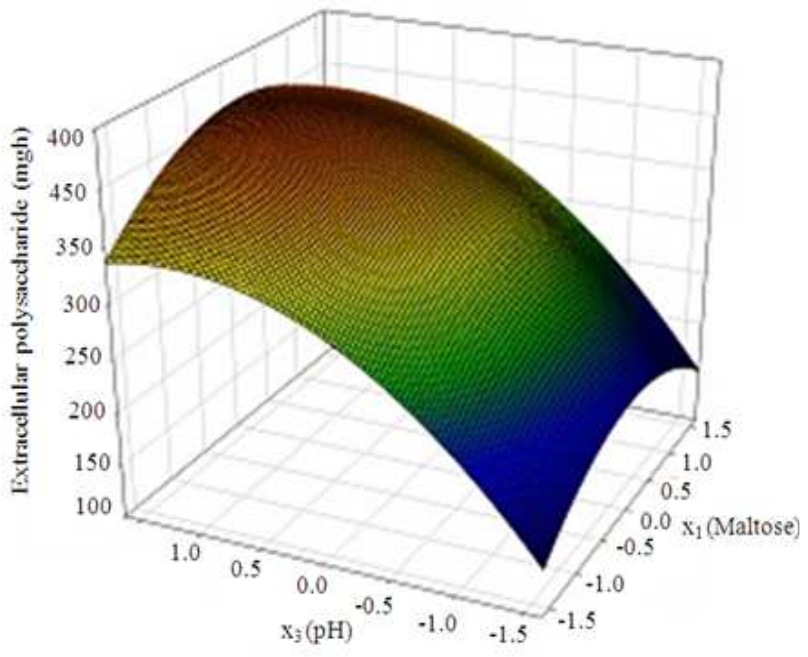

(b)

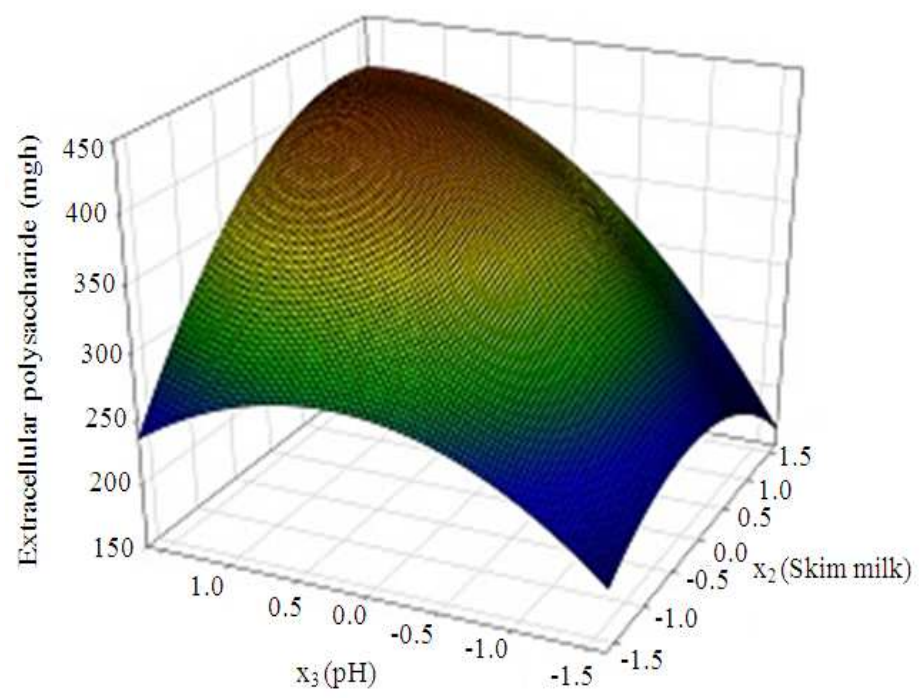

(c)

Fig. 1. Response surface 3D plot for EPS (mg/l) production of G. tsugae 


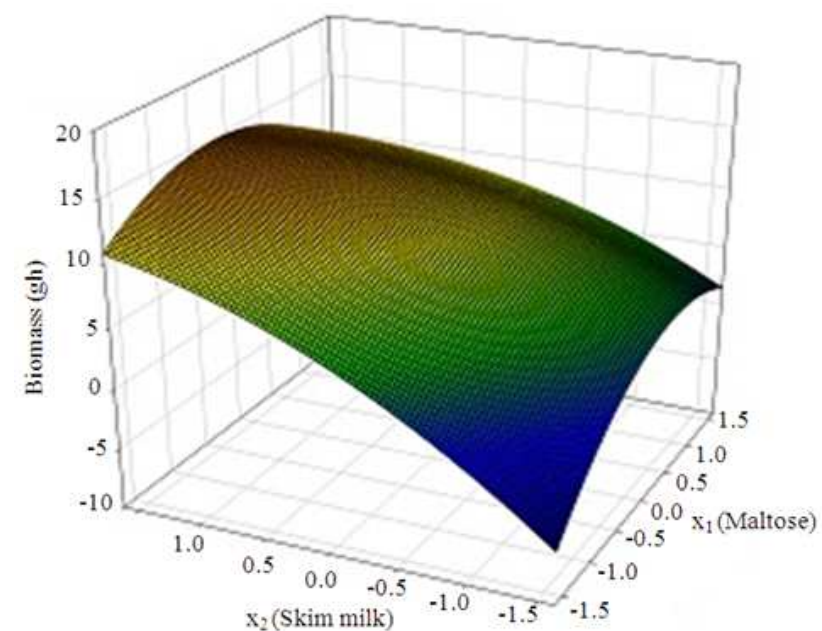

(a)

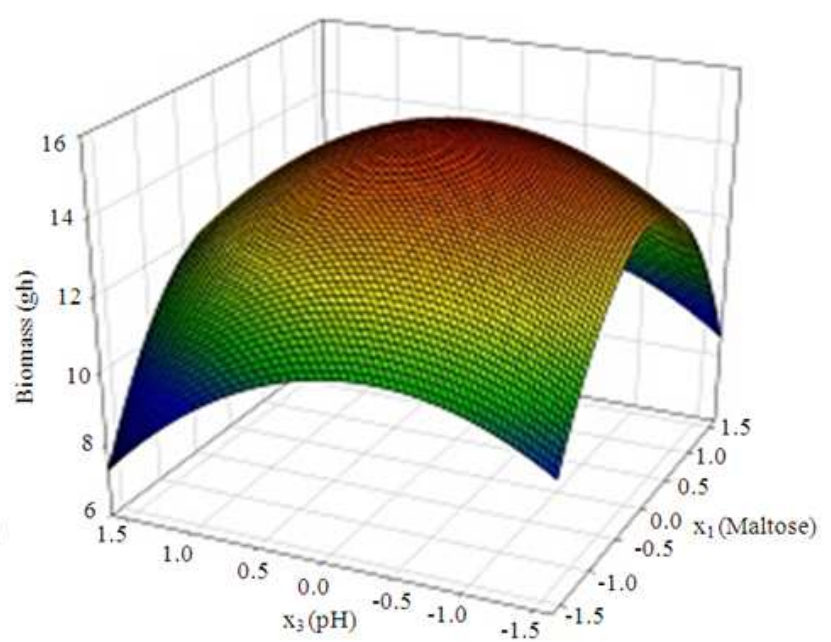

(b)

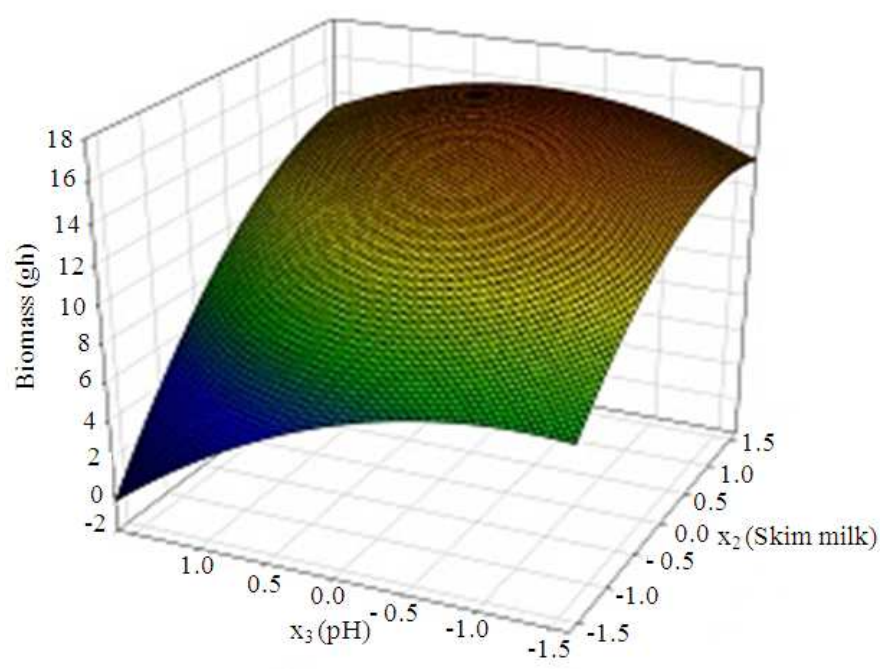

Fig. 2. Response surface 3D plot for biomass (g/l) of G. tsugae

\section{DISCUSSION}

Combination of statistical techniques consisted of screening by PBD, determination of optimal ranges by path of steepest ascent method and optimal searching by RSM was applied for optimization of submerged fermentation for EPS and biomass of $G$. tsugae. Combination of statistical techniques offers a strategy for studying many variables including nutrient requirements and culture conditions in fewer experimental runs, leading this method to be widely used to screen multiple variables of fermentation processes. Literature reviews of many studies on nutritional requirements for Ganoderma fungus has shown that a carbon source of brown sugar, a nitrogen source of skim milk, plant olive oil, $\mathrm{CaCO}_{3}$ (Chang et al., 2006), $\mathrm{MgSO}_{4} \cdot 7 \mathrm{H}_{2} \mathrm{O}, \mathrm{K}_{2} \mathrm{HPO}_{4}, \mathrm{KH}_{2} \mathrm{PO}_{4}$ (Hsieh et al., 2006) and ethanol (Yang et al., 2004) effectively promoted biomass and EPS. Moreover, cheese whey (Lee et al., 2003), brown sugar, skim milk (Chang et al., 2006) and molasses, increased production because these components contain various vitamins and other nutrients. Chang et al. (2006) showed that setting the $\mathrm{pH}$ and incubation temperature to 6.5 and $34^{\circ} \mathrm{C}$, respectively, increased the biomass and EPS of G. lucidum. In contrast, (Lee et al., 2003) reported that the optimal conditions for biomass by G. lucidum were $\mathrm{pH}$ 4.2 and $28.3^{\circ} \mathrm{C}$. Therefore, differences in the culture environment might have led to these different results. The data on G. tsugae production were subjected to multiple linear regression analysis and the coefficients, t- 
values, p-values and confidence levels were estimated. The first-order model (Equation 3) predicted that increasing the concentrations of maltose, skim milk, $\mathrm{KH}_{2} \mathrm{PO}_{4}+\mathrm{K}_{2} \mathrm{HPO}_{4}, \mathrm{MgSO}_{4} \cdot 7 \mathrm{H}_{2} \mathrm{O}, \mathrm{CaCO}_{3}, \mathrm{~B}_{5}+\mathrm{B}_{6}, \mathrm{pH}$ and shaking speed and decreasing the concentrations of other variables including $\mathrm{MgSO}_{4} \cdot 7 \mathrm{H}_{2} \mathrm{O}$, olive oil and ethanol could further enhance EPS. Furthermore, the effect value of each factor tested was assessed by a t-test, with the values and confidence levels presented in Table 2 indicating with high confidence levels that maltose, skim milk and $\mathrm{pH}$ are linked to EPS production. These three factors were selected as key factors for the next optimization step. While, the other factors including $\mathrm{KH}_{2} \mathrm{PO}_{4}, \mathrm{~K}_{2} \mathrm{HPO}_{4}, \mathrm{MgSO}_{4} \cdot 7 \mathrm{H}_{2} \mathrm{O}$, $\mathrm{CaCO}_{3}$, vitamin $\mathrm{B}_{5}+\mathrm{B}_{6}$, olive oil, ethanol and shaking speed were not the primary factors controlling EPS production. They did affect biomass and the yields of triterpeniod compounds with high confidence levels (data not shown), which could be used in the future to enhance the production of these compounds and study the pathway of G. tsugae production. Carbon and nitrogen sources play a significant role in determining the production level of submerged fermentation because these nutrients are directly linked with cell proliferation and metabolite biosynthesis (Kim et al., 2003; Zou, 2005). Maltose has been found to be best carbon source for the cell mass and EPS production in G. applanatum (Lee et al., 2007) and G. lucidum (Tang and Song, 2002), respectively, because it can be easily used for biosynthesis of biomass and EPS, as glucose is the main sugar component of the cellular energy production system and EPS. Skim milk is substrate for protease enzymes, such as fibriolytic enzymes (Silva et al., 2003; Korat and Rizvi, 2004; Albillos et al., 2007; Merheb et al., 2007), which Ganoderma species have the ability to (Jo et al., 2011; Kumaran et al., 2011) in order to digest complex protein molecules into simple polypeptide chains and amino acids (Sharma et al., 2011) for the growth and metabolic activities. Moreover, $\mathrm{pH}$ in submerged fermentation is important because enzymes involved fermentation operate in optimum $\mathrm{pH}$ environment (Hashemi et al., 2013; Zaman et al., 2009).

\section{CONCLUSION}

This study combined PBD, steepest ascent and CCD strategies to enhance $G$. tsugae yields. These methods not only helped to obtain the optimal combination of factors with fewer experiments, materials and time but also proved to be useful and satisfactory in studying the fermentation process. In submerged cultivation, factors like carbon source, nitrogen source and $\mathrm{pH}$ were shown to be highly influential, so the optimal ranges of these variables for maximum biomass and EPS were calculated and subsequently verified. The optimal condition, (31.031 $\mathrm{g} \mathrm{L}^{-1}$ maltose, $14.055 \mathrm{~g} \mathrm{~L}^{-1}$ skim milk and an initial $\mathrm{pH}$ of 7.12) yields approximately 13 and 1.5 times more biomass and EPS, respectively, when compared with the nonoptimized condition. This optimal condition will apply to culture $G$. tsugae in large scale of bioreactor in bioindustry. The fundamental information obtained in this study will be highly useful for efforts to optimize the fermentation process of $G$. tsugae for further basic scientific studies as well as for medicinal purposes.

\section{ACKNOWLEDGEMENTS}

This author was financially supported by a grant from National Pingtung University of Science and Technology, Taiwan.

\section{REFERENCES}

Albillos, S.M., M.D. Busto, M.P. Mateos and N. Ortega. 2007. Analysis by capillary electrophoresis of the proteolytic activity of a Bacillus subtilis neutral protease on bovine caseins. Int. Dairy J., 17: 11951200. DOI: 10.1016/j.idairyj.2007.02.003

Cansee, S., J. Uriyapongson, C. Watyotha, T. Thivavarnvongs and J. Varith, 2008. Amphoteric starch in simultaneous process preparation with boxbehnken design for optimal conditions. Am. J. Applied Sci., 5: 1535-1542. DOI: 10.3844/ajassp.2008.1535.1542

Chang, M.Y., G.J. Tsai and J.Y. Houng, 2006. Optimization of the medium composition for the submerged culture of Ganoderma lucidum by Taguchi array design and steepest ascent method. Enzyme Microbial Technol., 38: 407-414. DOI: 10.1016/j.enzmictec.2005.06.011

Hashemi, M., S.M. Mousavi, S.H. Razavi, S.A. Shojaosadati, 2013. Comparison of submerged and solid state fermentation systems effects on the catalytic activity of Bacillus sp. KR-8104 $\alpha$-amylase at different $\mathrm{pH}$ and temperatures. Ind. Crops Products., 43: 661667. DOI: $10.1016 /$ j.indcrop.2012.08.002

Hsieh, C., M.H. Tseng and C.J. Liu, 2006. Production of polysaccharides from Ganoderma lucidum (CCRC 36041) under limitations of nutrients. Enzyme Microbial Technol., 38: 109-117. DOI:10.1016/j.enzmictec.2005.05.004

Hsu, S.C., C.C. Ou, T.C. Chuang, J.W. Li and M.C. Kao et al., 2009. Ganoderma tsugae extract inhibits expression of epidermal growth factor receptor and angiogenesis in human epidermoid carcinoma cells: In vitro and in vivo. Cancer Lett., 281: 108-116. DOI: $10.1016 /$ j.canlet.2009.02.032 
Jo, W.S., H.N. Park, D.H. Cho, Y.B. Yoo and S.C. Park, 2011. Detection of extracellular enzyme activities in Ganoderma neo-japonicum. Mycobiology. 39: 118120. DOI: $10.4489 /$ MYCO.2011.39.2.118

Kim, S.W., C.P. Xu, H.J. Hwang, J.W. Choi and J.W. Yun et al., 2003. Production and characterization of exopolysaccharides from an enthomopathogenic fungus Cordyceps militaris NG3. Biotechnol. Progress., 19: 428-435. DOI: 10.1021/bp025644k

Korat, A.V.A. and S.S.H. Rizvi, 2004. Vatless manufacturing of low-moisture part-skim mozzarella cheese from highly concentrated skim milk microfiltration retentates. J. Dairy Sci., 87: 3601-3613. DOI: $10.3168 /$ jds.S0022 -0302 (04)73498-0

Kumaran, S., P. Palani, R. Nishanthi, S. Srimathi and V. Kaviyarasan, 2011. Purification of an intracellular fibrinolytic protease from Ganoderma Lucidum Vk12 and its susceptibility to different enzyme inhibitors. Tropical J. Pharmaceutical Res., 10: 413420. DOI: $10.4314 /$ tjpr.v10i4.6

Lee, H., M.Y. Song and S. Hwang. 2003. Production of Ganoderma lucidum mycelium using cheese whey as an alternative substrate: response surface analysis and biokinetics. Biochem. Eng. J., 15: 93-99. DOI: 10.1016/S1369-703X(02)00211-5

Lee, W.Y., Y. Park, J.K. Ahn, K.H. Ka and S.Y. Park, 2007. Factors influencing the production of endopolysaccharide and exopolysaccharide from Ganoderma applanatum. Enzyme Microbial Technol., 40: 249-254. DOI: 10.1016/ j.enzmictec.2006.04.009

Lin, K.W., Y.T. Chen, S.C. Yang, B.L. Wei and C.N. Lin et al., 2013. Xanthine oxidase inhibitory lanostanoids from Ganoderma tsugae. Fitoterapia, 89: 231-238. DOI: 10.1016/j.fitote2013.06.006

Merheb, C.W., H. Cabral, E. Gomes and R.D. Silva, 2007. Partial characterization of protease from a thermophilic fungus, Thermoascus aurantiacus and its hydrolytic activity on bovine casein. Food Chem., 104: 127-131. DOI: 10.1016/ j.foodchem.2006.11.010

Narkprasom, N., J.H. Guo, T.C. Huang and Y.K. Guu, 2012. The kinetic model for biomass and extracellular polysaccharide of Ganoderma tsugae. APCBEE Procedia., 2: 7-11. DOI:10.1016/j.apcbee.2012.06.002

Omar, R., M.A. Abdullah, M.A. Hasan and M. Marziah, 2004. Development of growth medium for Centella Asiatica cell culture via response surface methodology. Am. J. Applied Sci., 1: 215-219.DOI: 10.3844/ajassp.2004. 215.219
Rusell, R. and M. Paterson, 2006. Ganoderma-A therapeutic fungal biofactory. Phytochemistry, 67: 1985-2001. DOI: 10.1016/j.phytochem.2006.07.004

Sharma, A.K., V. Sharma and J. Saxena, 2011. Production of protease and growth characteristics of Aspergillus sydowii. Nature Sci., 9: 217-221.

Silva, S.V., T. Allmere, F.X. Malcata and A. Andren, 2003. Comparative studies on the gelling properties of cardosins extracted from Cynara cardunculus and chymosin on cow's skim milk. Int. Dairy J., 13: 559564. DOI: 10.1016/S0958-6946(03)00075-X

Tang, Y.J. and J.J. Zhong, 2002. Fed-batch fermentation of Ganoderma lucidum for hyperproduction of polysaccharide and ganoderic acid. Enzyme Microbial Technol., 31: 20-28. DOI: 10.1016/S0141-0229(02)00066-2

Xiao, J.H., D.M. Xiao, Q. Xiong, Z.Q. Liang and J.J. Zhong, 2010. Nutritional requirements for the hyperproduction of bioactive exopolysaccharides by submerged fermentation of the edible medicinal fungus Cordyceps taii. Biochem. Eng. J., 49: 241249. DOI: 10.1016/j.bej.2007.08.013

Xu, H.L., P. Sun, Y.Z. Shi, Y.H. Wu and D.Q. Zhao et al., 2008. Optimization of cultivation conditions for extracellular polysaccharide and mycelium biomass by Morchella esculenta As51620. Biochem. Eng. J., 39: 66-73. DOI: 10.1016/j.bej.2007.08.013

Yang, H.L., T.X. Wu and K.C. Zhang, 2004. Enhancement of mycelial growth and polysaccharide production in Ganoderma lucidum (the Chinese medicinal fungus, Lingzhi) by the addition of ehanol. Biotechnol. Lett., 26: 841-844.

Zaman, M.Z., A.S. Abdulamir, F.A. Bakar, J. Selamat and J. Bakar, 2009. A review: Microbiological, physicochemical and health impact of high level of biogenic amines in fish sauce. Am. J. Applied Sci., 6: 1199-1211. DOI: 10.3844/ajassp.2009.1199.1211

Zhang, C., D. Fan, L. Shang, X. Ma and P. Gao et al., 2010. Optimization of fermentation process for human-like collagen production of recombinant Escherichia coli using response surface methodology. Chinese J. Chem. Eng., 18: 137-142. DOI: $10.1016 / \mathrm{S} 1004-9541(08) 60334-1$

Zou, X., 2005. Optimization of nutritional factors for exopolysaccharide production by submerged cultivation of the medicinal mushroom Oudemansiella radicata. World J. Microbiol. Biotechnol., 21: 1267-1271. DOI: 10.1007/s11274005-1941-5 